Interactive comment on "The evaluation and enhancement of quality, environmental protection and safety in seaports" by D. Tadic et al.

D. Tadic et al.

pavle.popovic@portofkotor.co.me

Received and published: 22 August 2016 


\section{Response to the Reviewer's comment}

\section{Reviewer's comment}

I have to admit I found a bit cumbersome the reading of the paper, in the current form. In particular, I think too many technicalities are included in the main part of the paper, making complex the reading.

I would suggest the authors to restructure section 2.3 (algorithm) and section 4 (application) to make the paper more easily readable. I.e., one option would be to clarify the main steps (of the algorithm) and results (of the application) in the main part of the paper, moving the more technical issues to an appendix of the paper itself.

In the current version, I find difficult to judge the quality of the presented work.

\section{Response:}

We want to thank for the useful suggestions.

Authors have carefully analyzed the suggestions of reviewer. In that manner, authors have put significant effort to incorporate all suggestions into revised manuscript. We believe that the overall quality of the manuscript has been improved.

Printer-friendly version

Discussion paper 
Appendix has been added to the revised manuscript. It contains detailed calculation so only main results are presented in the revised manuscript. Sections related to presenNHESSD tation of the model and algorithm have been merged to single section in compliance to the reviewer's suggestions.

Please find enclosed, as a *pdf. file in the supplement, the revised manuscript.

Interactive

comment

We remain at your disposal for any further information.

Please also note the supplement to this comment:

http://www.nat-hazards-earth-syst-sci-discuss.net/nhess-2016-126/nhess-2016-126AC5-supplement.pdf

Interactive comment on Nat. Hazards Earth Syst. Sci. Discuss., doi:10.5194/nhess-2016-126, 2016. 